\title{
Participação e liberdade política em Hannah Arendt
}

\author{
Yara Frateschi*
}

\begin{abstract}
RESUMO:
Pretende-se, neste artigo, mostrar de que modo Arendt, mantendo-se fiel à sua posição antimarXista e À CRÍTICA CONTUNDENTE DA DEMOCRACIA FORMAL, COMBINA ELEMENTOS LIBERAIS E DEMOCRÁTICOS PARA DEFENDER UM MODELO DE ESTADO CONSTITUCIONAL, ONDE OS DIREITOS INDIVIDUAIS SEJAM GARANTIDOS AO MESMO TEMPO EM QUE SEJAM MANTIDOS ESPACOS DE LIBERDADE QUE PERMITAM AOS CIDADÃOS TORNAREM-SE, DE ALGUM MODO, PARTICIPAN-

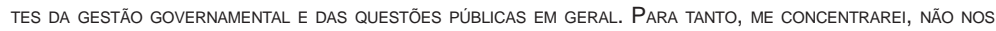
TEXTOS EM QUE ARENDT SE VOLTA PARA O TOTALITARISMO OU PARA A DITADURA, MAS NAQUELES (PRINCIPALMENTE DA REVOLUÇÃ̃o E DESOBEDIÊNCIA CIVIL) EM QUE SE DEDICA A REFLETIR SOBRE OS MODOS DE GERAR E AMPLIAR ESPAÇOS DE LIBERDADE EM UM CONTEXTO POLÍTICO EM QUE AS CONDIÇŌES PARA TANTO ESTÃO, EM CERTA MEDIDA, JÁ ESTABELECIDAS, COMO É O CASO DA REPÚBLICA AMERICANA.
\end{abstract}

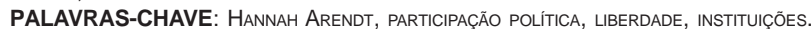

\section{ABSTRACT:}

THIS ARTICLE INTENDS TO SHOW HOW ARENDT COMBINES LIBERALS AND DEMOCRATIC ELEMENTS IN ORDER TO DEFEND A CONSTITUTIONAL STATE MODEL ABLE TO GUARANTEE INDIVIDUAL RIGHTS AND TO ESTABLISH SPACES OF LIBERTY, BY WHICH CITIZENS CAN PARTICIPATE OF PUBLIC QUESTIONS AND DECISIONS. TO DEMONSTRATE THE IMPORTANCE OF PUBLIC PARTICIPATION THIS ARTICLE INTENDS TO ANALYZE hOW THIS QUESTION APPEAR IN CIVIL DISOBEDIENCE AND ON REVOLUTION. KEYWORDS: HANNAH ARENDT, POLITICAL PARTICIPATION, LIBERTY, INSTITUTIONS.

1.

Nos textos Da Revolução, Desobediência Civil e Da Violência, o ponto de partida de Arendt é um diagnóstico de crise da democracia representativa, produzida pela burocratização e perda de poder das instituições e, em conseqüência, pela diminuição dos espaços de liberdade por meio dos quais os cidadãos podem agir e se fazer ouvir. A burocracia é "a forma de governo na qual todo mundo é destituído de liberdade política, do poder de agir"; ${ }^{1}$ onde ela comanda, o poder cede à violência, já que onde não há ninguém com quem se possa argumentar, tampouco há espaço para a expressão, discussão e decisão conjunta. Mas Arendt

\footnotetext{
- Agradeço a Marisa Lopes e a Bruno Nadai pelas conversas e pelas valiosas sugestões (e provocações). Agradeço também a Renata Romolo Brito e a Luiz Diogo de Vanconcelos Junior, na companhia dos quais venho enfrentando os textos tortuosos de Hannah Arendt.

** Professora doutora do Departamento de Filosofia da Unicamp.

${ }_{1}^{1}$ Arendt, H. Crises da República. São Paulo: Editora Perspectiva, 1973, p. 151. As citações dos textos Da Violência e Desobediência Civil serão feitas a partir desta edição brasileira de Crises da República (que os reúne).
} 
não se contenta, nestes textos, em apontar a crise e as suas causas, em detectar os defeitos do sistema representativo e de partidos, em maldizer a sociedade de massas e sua futilidade consumista. O passo seguinte - e que nos interessa particularmente neste artigo - é detectar onde se localiza a possibilidade de recuperação da capacidade de agir, cujos mecanismos estão enferrujados ou esquecidos, mas não inteiramente eliminados, ao menos no que diz respeito à república norte-americana, onde ainda existem, apesar da crise, condições favoráveis para a liberdade. A convicção de que os Estados Unidos estabeleceram, desde a sua fundação, espaços públicos de liberdade, que podem ser restabelecidos, é manifestada por Arendt explicitamente desde a década de cinqüenta, em Da Revolução, em 1969, em Da Violência e mantida até o final de sua vida. Em 1973, defendendo com ardor a Constituição americana, diz sentir-se "perfeitamente livre neste país". ${ }^{2}$

Duas observações para evitar equívocos. Em primeiro lugar, deve-se manter a distinção entre a república em crise e o sistema totalitário. Quando Arendt se volta para a primeira, particularmente no caso dos Estados Unidos, ela faz questão de mostrar que há, de alguma maneira (mais ou menos precária, mas há), as condições básicas para que os cidadãos, no "espírito" da Revolução Americana, retomem a sua capacidade de ação e recuperem a sua liberdade. Dentre tais condições, desempenham papel fundamental a Constituição americana e demais instituições, como a Suprema Corte, o Senado, para citar dois exemplos. Posto que a república em crise esteja muito longe de uma ditadura ou do totalitarismo, trata-se, então, de pensar como sair da crise ou lidar com os seus efeitos mais perversos dentro da sua própria estrutura. O problema não é a constituição e não está nas liberdades e nos direitos civis "apenas formais", que são, ao contrário, a condição necessária (ainda que não suficiente) da vida política. O problema está, sim, na restrição da participação política e dos seus mecanismos, que devem ser recuperados e devem poder conviver com a lei e com as instituições americanas.

Para que se pense sobre a compatibilidade entre as instituições -

${ }^{2}$ Apud Adler, L. Nos Passos de Hannah Arendt. São Paulo: Record, 2007, p. 545. 
que dão estabilidade ao corpo político - e a participação do povo, é preciso lembrar que, para Arendt, deve haver um equilíbrio entre natalidade (novidade) e permanência, capaz de garantir a entrada do novo no mundo. Para que venha o novo é preciso um contexto de estabilidade, e esta estabilidade é garantida, sobretudo, pela constituição e pelas instituições que por ela zelam. A estabilidade não pode se converter, entretanto, em enrijecimento: é preciso haver espaços de abertura pelos quais o novo possa vir a ser e se instaurar. Destarte, a constituição e os legisladores, os governantes e os representantes, responsáveis em grande medida pela estabilidade, não podem estar cegos, surdos e mudos para o novo (ou para o velho que, finalmente, aparece). Neste processo, a participação ativa de cidadãos organizados desempenha papel fundamental, como veremos.

Em segundo lugar, deve-se observar que Arendt, ao diagnosticar a crise sem, contudo, propor a revolução como saída, não adota, por isso, uma postura resignada ou se contenta em apontar meios que visam apenas deter o avanço da deterioração. A revolução já foi feita e ela foi triunfante, dando origem a uma república livre. É preciso, agora, recuperar o 'espírito' da revolução americana, ou seja, lembrar e fazer reviver a conquista de liberdades verdadeiramente políticas, tais como a liberdade de expressão e pensamento, de reunião e associação, as quais não deixam dúvida da grandeza e superioridade dessa revolução em relação à revolução russa, que fez nascer uma tirania. A grandeza está no fato de que a revolução americana criou as condições para a política, enquanto a russa a fez desaparecer. Então, que se "faça" política. E política se faz com debate e associação, enfim, com participação ativa num ambiente que só se sustenta como um ambiente político porque é plural. Isso posto, a reclusão e a recusa de agir e participar da esfera pública são, talvez, aceitáveis em situações extremas, ${ }^{3}$ como na ditadura ou no totalitarismo, mas não são exemplares numa

\footnotetext{
${ }^{3}$ Ver Duarte, A. "Hannah Arendt e a exemplaridade subversiva: por uma ética pósmetafísica". Cadernos de Filosofia Alemã, n. 9, 2007, p.27-48. André Duarte pretende, neste artigo, revelar uma "faceta menos conhecida" da reflexão de Arendt que, apesar de ser considerada uma pensadora por excelência do espaço público, "estava consciente de que a exemplaridade subversiva também se manifesta nos silêncios ponderados e na recusa discreta dos cidadãos anônimos em obedecer àquilo que o governo ou a sociedade deles espera e que, entretanto, lhes parece injusto, aviltante ou incorreto"
} 
república, mesmo em crise. Pelo contrário, Arendt nos faz ver que a mobilização dos cidadãos, seja com a intenção de preservar o status quo ou de promover mudanças necessárias ou desejadas, ganha poder e eficácia quando estes se associam e se organizam tornando-se capazes de se fazer ouvir e de pressionar o governo.

\section{2.}

Nas linhas que seguem, pretendemos recuperar, ainda que brevemente, a comparação entre a Revolução Americana e a Francesa feita por Arendt, em Da Revolução, sobretudo com a intenção de ressaltar que a experiência americana da fundação aparece na obra como exemplo de participação ativa na vida política: os homens da revolução são exemplares porque permaneceram "homens de ação do princípio ao fim, da declaração da Independência à organização da Constituição". ${ }^{4}$

Por meio da distinção entre liberdade e libertação Arendt mobiliza os argumentos de que precisa para ressaltar a grandeza e superioridade da revolução americana em relação à francesa e também à russa. A libertação de um povo exige uma série de conquistas - no plano dos direitos - que o liberte da repressão e da intervenção arbitrária do governo. A libertação, pode-se dizer, é a conquista da liberdade na sua acepção negativa, garantida pelos direitos civis. Entretanto, ela não pode ser confundida com liberdade política propriamente dita, pois esta consiste em dar um passo além, na medida em que "o verdadeiro conteúdo da liberdade significa participação nas coisas públicas, ou admissão ao mundo político". ${ }^{5}$ Porque a liberdade - para além da libertação - era a verdadeira meta dos americanos, fez-se necessária e possível a descoberta de uma nova forma de governo, "a constituição de uma república". Ao dis-

(p. 35). Parece-me, contudo, que Arendt aceita a resistência silenciosa como um último recurso que resta aos cidadãos quando estão privados da possibilidade de agir e que, portanto, é exemplar apenas na ditadura ou no totalitarismo, mas não em uma democracia. Na democracia, os homens são cidadãos quando agem, quando manifestam as suas opiniões em palavras e ações, dialogando com os outros e não apenas consigo mesmos.

${ }^{4}$ Arendt, H. "Desobediência Civil". In: ___. Crises da República, p. 75.

${ }^{5}$ Arendt, H. Da Revolução. São Paulo: Editora Ática, 1990, p. 26. 
tinguir liberdade e libertação, Arendt quer atacar, com um só golpe, marxistas e liberais. Mesmo que fosse possível, a libertação do trabalho não levaria, por si só, à liberdade, garante ela. Aliás, pelo contrário, ela levaria, na expectativa de Marx, a uma vida em que a liberdade política já não teria sentido algum. ${ }^{6}$ De outro lado, a liberdade dos liberais não é liberdade, mas libertação, que garante tão somente as condições apropriadas para uma vida vivida na 'privatividade'. Em ambos os casos, vige a ficção de uma harmonia de interesses, que é antipolítica e contrária à pluralidade. ${ }^{7}$

Ainda que não possa ser tratada com a merecida atenção neste artigo, deve-se destacar que a questão da pobreza desempenha papel central em Da Revolução, mas não porque Arendt se dedica a pensar de que modo resolvê-la e sim porque está determinada a recusar que a pobreza seja questão política. As insuficiências da noção arendtiana de poder e do seu modo de pensar a relação entre o político e o social se fazem ver aqui: só dá para fazer política se o problema da pobreza estiver ausente ou resolvido, mas não sabemos exatamente como ele se resolve, já que não é e não pode ser questão política. Basta, no presente momento, lembrar que, para Arendt, a premência da pobreza e a conseqüente redução do político ao econômico e ao social foram as causas principais do fracasso da revolução na França. A redução do político ao econômico (ou a transformação da questão social na questão política

\footnotetext{
6 "Provavelmente, nem a abundância de bens, nem a redução do tempo gasto com o labor resultarão no estabelecimento de um mundo comum; o animal laborans expropriado não se torna menos privado pelo fato de já não possuir um lugar privativo onde possa esconder-se e proteger-se da esfera comum. Marx predisse, embora com indevido júbilo, a 'decadência' da esfera pública nas condições de livre desenvolvimento das 'forças produtivas da sociedade'; e estava igualmente certo, isto é, coerente com a sua noção de homem como animal laborans quando previu que, 'socializados' e libertos do trabalho, os homens gozariam essa liberdade em atividades estritamente privadas e essencialmente isolados do mundo que hoje chamamos de 'hobbies"'. Arendt se refere aqui à da Ideologia Alemã: "Na sociedade comunista ou socialista", continua ela, "todas as profissões se tornariam uma espécie de hobby: não haveria pintores, mas apenas pessoas que, entre outras coisas, passam parte do tempo pintando; ou seja, pessoas que 'hoje fazem uma coisa, amanhã fazem outra, que caçam pela manhã, pescam à tarde, criam gado ao anoitecer, são críticos após o jantar, a seu bel-prazer, sem por isso jamais chegarem a ser caçadores, pescadores, pastores ou críticos'”. Arendt, H. A Condição Humana. Rio de Janeiro: Forense Universitária, 2003, p. 130.

${ }^{7}$ Arendt, H. A Condição Humana, p. 53.
} 
por excelência) é também a fonte do engano de Marx, que "acabou por enfatizar, mais do que qualquer outro, a doutrina politicamente mais perniciosa da Idade Moderna, ou seja, que a vida é o bem maior, e que o processo vital da sociedade é o próprio centro do esforço humano". ${ }^{8}$ Arendt não esconde que exalta o aspecto democrático da revolução americana para falar contra a "tirania" russa ou que acusa o insucesso da experiência francesa para falar contra os marxistas e toda a esquerda que ainda acalenta o sonho (daquela) da revolução. Ela quer, ao mesmo tempo, ressaltar o fracasso político da revolução francesa com a instauração do terror e lembrar que a solução de Marx também levaria, ao fim e ao cabo, à destruição da política, como levou, por sua vez, a revolução Russa. ${ }^{9}$ Eis a razão pela qual Arendt insiste na separação, "inteiramente não-marxista, entre economia e política"10 (sem nenhum constrangimento em dizer apenas que uma boa solução para o problema da pobreza se dá por meios técnicos, já que a tecnologia é "politicamente neutra").

O sucesso político da revolução americana se deve, então, à ausência, naquele contexto, de carências "avassaladoras", que teriam impedido (como foi o caso da França) que a política ganhasse a autonomia que ela deve ter em relação à questão social:

Já que não existia, em torno deles [dos americanos], nenhum sofrimento que pudesse ter despertado suas paixões, nem carências avassaladoramente prementes que os levassem a se submeter à necessidade, nem piedade para desviá-los da razão, os homens da revolução Americana permaneceram homens de

\footnotetext{
${ }^{8}$ Arendt, H. Da Revolução, p. 51.

${ }^{9} \mathrm{Da}$ Revolução diz a que veio em seu capítulo final: mostrar que as conquistas americanas de liberdades verdadeiramente políticas, tais como a liberdade de expressão e pensamento, de reunião e de associação, não deixam dúvidas da grandeza e superioridade de uma república livre em relação à tirania. A referência é a Rússia e a pergunta é: qual é a melhor forma de governo, uma tirania ou uma república livre? Arendt responde comparando as instituições de liberdade "nascidas da vitória triunfante de uma revolução" e as várias formas de dominação "da ditadura de um partido, de Lênin, ao totalitarismo de Stalin e às tentativas de Krushev em direção a um despotismo iluminado, que apareceram na esteira de uma derrota revolucionária". Arendt, H. Da Revolução, p.174.

${ }_{10}$ Idem, p. 52.
} 
ação do princípio ao fim, da Declaração da Independência à or-

ganização da Constituição. ${ }^{11}$

A presença inegável da pobreza e da miséria fez com que a revolução francesa se baseasse mais na compaixão e na "fé na bondade natural" do que nas instituições. Mas a compaixão é, segundo Arendt, inteiramente irrelevante do ponto de vista político porque incapaz de estabelecer instituições duradouras e também é inadequada para modificar as condições materiais, pois quando o faz "elimina os demorados e extenuantes processos de persuasão, negociação e acordo, que são processos da lei e da política, e empresta sua voz ao próprio sofrimento, que deve clamar por ação direta e rápida, isto é, ação com meios de violência". ${ }^{2}$ Abstendo-se de refletir sobre as causas e as soluções das carências materiais, Arendt quer reforçar sobretudo que os processos da lei e da política são demorados e se consolidam não sem dificuldade - e assim deve ser - porque o poder é a capacidade humana de agir em conjunto, isto é, de comum acordo. A obtenção do acordo é precedida por um processo em que as diferenças são atenuadas e não eliminadas, até que se atinja, por persuasão e negociação, um ponto em que elas possam conviver no espaço público: um ponto comum, mas que jamais elimina a pluralidade. Foi isso precisamente o que aconteceu nos Estados Unidos, para Arendt (e se assim se deu foi justamente porque as diferenças que ela exalta não são, evidentemente, aquelas provocadas pela pobreza, questão ausente daquele cenário). Enquanto na França apostou-se na vontade popular, como volonté générale, isto é, numa inatingível e fictícia unidade da vontade que substitui o consentimento, os fundadores da república americana entendiam o povo como uma coletividade de infindável variedade, "cuja majestade residia em sua própria pluralidade". ${ }^{13}$ Não apostavam na unanimidade potencial de todos, pois sabiam que "o plano político, numa república, se constituía numa troca de opiniões

\footnotetext{
11 Idem, p. 75.

12 Idem, p. 69.

${ }_{13}$ Idem, p. 74.
} 
entre iguais, e que esse plano desapareceria no próprio instante em que se tornasse supérfluo, se por acaso todos os iguais fossem da mesma opinião". Todo o argumento que se segue à análise da experiência americana converge para mostrar que a igualdade almejada e que pode ser alcançada é tão somente política, isto é, se dá no plano dos direitos: para além disso o que temos é a pluralidade, que não pode jamais ser eliminada. Nesse sentido, os fundadores haviam dado uma ênfase positiva à facção e ao partido, que correspondem, no governo, às múltiplas vozes e diferenças de opinião que devem ter espaço para continuar existindo.

A defesa da democracia participativa encontra sustentação teórica na definição de ação como única faculdade humana que demanda uma pluralidade de homens e de poder como único atributo humano que só tem aplicação no espaço intermundano. ${ }^{14}$ No plano histórico, a Declaração da Independência e a Constituição dos Estados Unidos são a prova de que os homens podem construir uma nova ordem política em que a ação (no contexto da pluralidade) e o poder (indissociado da liberdade e executado no espaço intermundano) são perfeitamente possíveis, exeqüíveis. A própria noção de constituição, tal como entendida pelos americanos, o demonstra: a constituição não é ato de um governo, mas de um povo que constitui um governo. ${ }^{15} \mathrm{E}$ para que se concretizasse, e este é o ponto fundamental, não foi possível prescindir de ampla discussão e debate dos seus artigos, tanto no plano municipal, quanto no estadual. ${ }^{16}$ Debate, confronto de opiniões, busca de acordo num universo plural: através de um longo processo, a ação levou à formação do poder. Foi o ambiente propício ao autogoverno que, inicialmente, o permitiu; e a fundação de um novo governo, baseado no princípio da sepa-

\footnotetext{
14 "A gramática da ação: a ação é a única faculdade humana que demanda uma pluralidade de homens; e a sintaxe do poder: o poder é o único atributo humano que só tem aplicação no espaço intermundano, em cujo âmbito os homens se relacionam mutuamente, se associam no ato de criação, por força das promessas feitas e cumpridas, as quais, na esfera política, podem muito bem ser a expressão da mais elevada das faculdades humanas". Idem, p. 140.

15 Idem, p. 116

${ }^{16}$ O país estava articulado "desde as províncias ou Estados, até as cidades e municípios, vilas e comarcas, em organismos devidamente constituídos”. Idem, p. 140.
} 
ração e equilíbrio de poderes, bem como na substituição da soberania pela Federação, deu continuidade ao empreendimento:

\begin{abstract}
Nesse aspecto, o curso da Revolução Americana nos mostra um exemplo inesquecível e nos ensina uma lição sem precedentes, pois essa revolução não eclodiu simplesmente, mas foi antes conduzida por homens que tomaram juntos uma resolução, unidos pela força de compromissos mútuos. O princípio veio à luz durante os conturbados anos em que foram lançadas as fundações - não por determinação de um arquiteto, mas pelo poder combinado de muitos - foi o princípio interconexo da promessa mútua e da deliberação comum (...). ${ }^{17}$
\end{abstract}

Ao mesmo tempo em que o novo governo estava configurado para assegurar a todo cidadão o direito de tornar-se participante da gestão governamental, contrapunha-se à identificação da felicidade com a felicidade exclusivamente individual. Não que, nos Estados Unidos, as noções de "felicidade pública" e "liberdade política" não tenham sofrido posteriormente duros golpes em favor da felicidade e da liberdade individuais. Aliás, este é um perigo a que está sujeito todo governo constitucional: erigir leis que protejam os cidadãos dos abusos do poder público tão somente para que estes possam cuidar dos seus negócios privados. Deste momento em diante, a liberdade migra da esfera pública para a vida particular e o poder passa a se identificar com a violência, isto é, com relações de comando e subordinação. O governo deixa de contar com a participação dos cidadãos e passa a ser considerado um mal necessário, fazendo com que a política perca o seu significado. Eis o problema do liberalismo.

O problema é que a revolução americana, embora tivesse dado liberdade ao povo, não conseguiu proporcionar um espaço onde essa liberdade pudesse ser exercida: "apenas os representantes, e não o próprio povo, tiveram uma oportunidade de se engajar nas atividades de 'expressão, discussão e decisão', as quais, num sentido positivo, são as

\footnotetext{
17 Idem, p. 171. Grifo meu.
} 
atividades da liberdade". ${ }^{18}$ Ainda que o Senado e a Suprema Corte, por exemplo, tenham sido fundamentais na medida em que se configuram como instituições que dão a permanência e a estabilidade necessárias para uma república, por outro lado, isso não foi suficiente para preservar intacto o espírito da revolução e garantir a participação do povo que sucumbiu à vitória do sistema de partidos.

\section{3.}

Em Da Revolução, Arendt quer, sobretudo, mostrar que os Estados Unidos tiveram uma experiência de liberdade política plena, ainda que não tenham sido capazes de encontrar, posteriormente, um modo apropriado de organização política. O problema do sistema de partidos e da representação é transformar a democracia numa mera formalidade. A democracia "abstrata" - isto é, aquela que carece de órgãos concretos de participação política que permitam ao povo se engajar nas atividades de expressão, discussão e decisão - trai o espírito da revolução ao permitir que a representação se torne um mero substitutivo para a ação política direta. ${ }^{19}$ Contudo, importa notar que os momentos de pessimismo revelados nas infindáveis críticas à sociedade de consumo e ao esquecimento americano do espírito revolucionário não pesam mais na balança do que a expectativa da recuperação de algo que não foi inteiramente eliminado desde a revolução:

A conseqüência, em contraposição ao desenvolvimento europeu, foi que as noções revolucionárias de felicidade pública e de liberdade política jamais desapareceram totalmente do cenário americano; elas se tornaram parte integrante da própria estrutura do corpo político da república. Se essa estrutura possui uma base granítica, capaz de suportar as fúteis artimanhas de uma sociedade voltada para a abastança e para o consumo, ou se ela cederá ante a pressão da riqueza, como as comunidades européias capitularam sob o jugo da desgraça e do infortúnio, é algo que só

\footnotetext{
${ }^{18}$ Idem, p.188.

${ }^{19}$ Arendt, H. Da Revolução, p. 189.
} 
o futuro poderá dizer. Existem hoje tantos sinais que justificam a

esperança, como há indícios que infundem o medo. ${ }^{20}$

Em Desobediência Civil não se trata mais de procurar as causas do sucesso ou do insucesso da revolução, mas sim de mostrar de que modo a participação dos cidadãos se dá, em casos concretos, na organização das minorias e da oposição, em atos de contestação civil e nos movimentos pelos direitos civis. A crítica ao sistema de partidos e à democracia abstrata nunca some do seu horizonte. Contudo, este texto não vem para lamentar a vitória do sistema de partidos sobre o de conselhos, mas para exaltar exemplos concretos de participação dos cidadãos na política: "minha discussão é que os contestadores civis não são mais do que a derradeira forma de associação voluntária, e que deste modo eles estão afinados com as mais antigas tradições do país", ${ }^{21}$ diz ela. Trocando em miúdos, Arendt quer saber o que é possível fazer, no contexto atual - ou seja, no contexto de uma democracia representativa, baseada na divisão de poderes e no sistema de pesos e contrapesos para que se chegue o mais perto possível de uma democracia participativa. Se à primeira vista parece um contra-senso, Arendt faz ver o contrário: é evidente que o sistema atual tende a limitar a participação, mas, por outro lado, não a elimina completamente quando os cidadãos se tornam efetivamente capazes de pressionar os seus representantes.

O lema é o mesmo: "liberdade política ou significa participar do governo ou não significa nada”. ${ }^{22}$ Importa agora mostrar, a partir de exemplos, que a participação é o antídoto contra a burocratização e a vitória da "liberdade" liberal sem, contudo (e como sempre), negar as conquistas liberais. Ela se concretiza na medida em que os cidadãos cavam espaços de liberdade que lhes permitem impedir a transformação do poder em violência, isto é, que permitem garantir que o poder seja de algum modo construído pelo povo. Arendt sabe que as instituições tendem a se enrijecer e impedir a assimilação de novas exigências e de-

\footnotetext{
${ }^{20}$ Idem, p. 110.

${ }^{21}$ Arendt, H. "Desobediência Civil". In:

${ }^{22}$ Arendt, H. Da Revolução, p. 175. Crises da República, p. 85.
} 
mandas, mas sabe também que elas são necessárias para a entrada do novo na política. Assim sendo, a solução requer o equilíbrio (ou ainda, o jogo) entre permanência e novidade e, para tanto, exige-se, ao mesmo tempo, solidez das instituições e participação dos cidadãos.

Arendt encontra, em 1968, um exemplo claro de ação política, quando a oposição dentro do senado americano se aliou à oposição nas ruas provocando "uma extraordinária mudança na política". ${ }^{23} \mathrm{~A}$ investida "imperialista" sofreu um duro golpe na medida em que a oposição se organizou e foi capaz de produzir resultados políticos efetivos. Deve-se registrar que a mudança se torna possível com a organização da oposição e não com a abolição do sistema. O que temos, neste texto, é um elogio da contestação civil mediante a prova da sua eficácia contra a opressão e a arbitrariedade do governo e para promover mudanças significativas e ganhos no plano dos direitos. A contestação civil se justifica no caso da guerra do Vietnã, contra freqüentes ameaças às liberdades garantidas pela Primeira Emenda ou ainda nas tentativas de privar o senado de seus poderes constitucionais, para citar alguns exemplos. O esforço de Arendt está voltado para desfazer a identificação do contestador com um criminoso ou ainda, de outro lado, com um revolucionário. Diferentemente do criminoso, ele age abertamente e desafia a autoridade em público, quando esta age ilegalmente ou arbitrariamente. Diferentemente do revolucionário, aceita a estrutura da autoridade estabelecida e a legitimidade geral do sistema de leis. ${ }^{24}$ É, pois, nos exemplos de contestação civil e de ação das minorias organizadas que Arendt detecta um valioso mecanismo de proteção contra a arbitrariedade do governo e de promoção de ganhos e mudanças. São formas de associação voluntária que conseguem fazer frente ao poder da maioria na medida em que se constituem como grupos de pressão (e são reconhecidos em Washington). ${ }^{25}$

Os movimentos pelos direitos civis são exemplares. Tome-se o movimento contra o racismo nos Estados Unidos, que foi, aponta Arendt,

\footnotetext{
${ }^{23}$ Arendt, H. "Da Violência". In: Crises da República, p. 155.

${ }^{24}$ Arendt, H. "Desobediência Civil". In: ___ Crises da República, p. 70.

${ }^{25}$ Idem, p. 85.
} 
responsável pela mudança de atitude da Suprema Corte em relação à imposição da igualdade racial. ${ }^{26} \mathrm{Ou}$ ainda os movimentos operários, que desempenharam papel "extraordinariamente produtivo" na política moderna. ${ }^{27}$ Não se trata de discutir aqui o perigo de enrijecimento, burocratização e perda conseqüente de poder dos movimentos, para o qual Arendt alerta constantemente. O perigo é verdadeiro, mas nem por isso ela recusa a eficácia e a virtude desses movimentos, sendo que a sua virtude está justamente na capacidade de promover mudanças sem abolir o sistema, ou seja, na sua capacidade de reformá-lo e de garantir direitos para aqueles que estão fora do sistema legal. Importa ressaltar, sobretudo, que o ganho não é só no plano dos direitos, mas na possibilidade mesma de ação e de formação constante do poder. Os movimentos, a associação voluntária, a organização das minorias e da oposição levam à libertação e são, simultaneamente, a própria expressão da liberdade.

A associação é, portanto, mecanismo de proteção e inclusão das minorias, de garantia de direitos e é também o dispositivo por meio do qual se testa continuamente a legitimidade do poder do Estado e das instituições, evitando que este se transforme em violência. O poder, que corresponde à capacidade humana de agir em conjunto, nunca é propriedade de um indivíduo e se constitui onde as pessoas se unem e agem em comum acordo. Numa democracia representativa, a possibilidade da associação voluntária dos cidadãos que se organizam para, de algum modo, pressionar o governo, é uma maneira de testar a efetividade ou permanência do acordo, isto é, a legitimidade do poder: "é o apoio do povo que empresta poder às instituições de um país, e este apoio não é mais que a continuação do consentimento que, de início, deu origem às leis". ${ }^{28}$ Nota-se, desse modo, que a participação popular - ou a associação para a contestação - é o teste de legitimidade do sistema político. Na medida em que a legitimidade se mede através da participação, sendo que participação é contestação (ou seja, é trazer a mudança para

\footnotetext{
${ }^{26}$ Idem, p. 74.

${ }^{27}$ Arendt, H. A Condição Humana, p. 227.

${ }^{28}$ Arendt, H. "Da Violência". In: Crises da República, p.120 (grifo meu).
} 
dentro do sistema), tanto mais legítimo é o sistema político quanto mais ele é aberto à mudança, quanto menos enrijecido em mecanismos de poder "abstratos".

\section{4.}

Arendt é freqüentemente retratada como uma autora obcecada pelo totalitarismo, que busca nostalgicamente na antiguidade as soluções para os problemas de seu tempo. Ela é em grande parte responsável por essa leitura. Quando o que mais se ressalta é a experiência ou um valor da antiguidade - e ela o faz com freqüência -, a proposta parece mesmo nostálgica e ingênua. Mas se essa é uma leitura que parece de fato encontrar sustentação a partir da formulação das noções de poder e política presentes em A Condição Humana, talvez não faça justiça às discussões levadas a cabo em Desobediência Civil e Da Violência. Não pretendo negar a pertinência da crítica de Habermas quando diz que o modelo arendtiano de ação, que é comunicativo, perde a sua força e adequação às sociedades contemporâneas quando se contrapõe integralmente aos elementos estratégicos do poder e não aceita a intrusão de questões econômicas e sociais na esfera pública. ${ }^{29}$ Se Arendt insiste, com razão, diz Habermas, que a superação da pobreza não é condição suficiente para que se assegure a liberdade política, por outro lado, o seu conceito de política é inaplicável e leva a absurdos, na medida em que ela quer dispensar o Estado da administração dos problemas sociais e quer "limpar" a política das questões econômicas e sociais. De fato, a radicalidade de Arendt ao tentar resgatar a autonomia da política acaba dando razão a Habermas. Mais do que recusar que as questões econômicas se sobrepõem à política e a determinam integralmente, a política se torna de tal modo autônoma que nada tem a fazer com elas. Entretanto, mesmo que se aceite, o que parece inevitável, as insuficiências da noção arendtiana de poder, o que se pretende aqui é fazer ver que Arendt encontra nos movimentos pelos direitos civis, na organiza-

${ }^{29}$ Habermas, J. "Hannah Arendt's Communications Concept of Power". In: Social Research, 1977, p.3-24. 
ção das minorias, enfim, na associação dos cidadãos, mecanismos de pressão eficazes, capazes de evitar a ditadura da maioria ou os abusos de poder e, ao mesmo tempo, de produzir ganhos efetivos para grupos alijados do consensus universalis original da República. Neste momento, talvez mais do que em qualquer outro, Arendt dialoga intensamente com as questões do seu tempo, apontando os mecanismos que dão aos cidadãos a possibilidade de participação na esfera pública.

Para terminar, uma palavra sobre o elogio ao sistema de conseIhos, que também alimenta - com alguma pertinência - a crítica que aponta a incapacidade de Arendt de propor uma solução plausível para o problema da democracia formal. $\mathrm{O}$ elogio aos conselhos, assim como ao sistema distrital, ${ }^{30}$ vem na esteira da constatação de que a concentração de "poder" nas mãos dos representantes faz do povo participante apenas nos momentos da eleição. Os conselhos, órgãos de ação que se formaram na França, na Rússia, na Alemanha e na Hungria, para citar alguns exemplos ${ }^{31}$ surgiram espontaneamente e se configuraram como órgãos de ordenamento e ação, cujos membros podiam debater e se esclarecer mutuamente sobre as medidas tomadas pelos partidos e assembléias; proporcionaram, enfim, a participação dos cidadãos nos assuntos públicos do país. Enquanto existiram, diz Arendt, não há dúvida de que "todo indivíduo encontrou neles sua própria esfera de ação e pôde constatar, como que com seus próprios olhos, sua contribuição pessoal aos acontecimentos do dia". ${ }^{32} \mathrm{~A}$ grande vantagem era a sua independência dos partidos: por serem acessíveis a todos, independentemente das linhas e filiações partidárias, os conselhos se constituíam como espaços de liberdade. Antes de almejarem um paraíso na terra, uma sociedade sem classes ou o sonho de uma fraternidade socialista ou comunista, desejavam sobretudo o estabelecimento "da verdadeira república". ${ }^{33}$

Parece, contudo, que Arendt não tem verdadeiramente a expectativa de que o sistema de partidos venha a ser substituído pelo de conselhos. Seria melhor, mas improvável ou até mesmo impossível nas con-

\footnotetext{
${ }^{30}$ Cf. Arendt, H. Da Revolução, p. 203.

${ }^{31}$ Idem, p. 209.

32 Idem, p. 210

${ }^{33}$ Idem, p. 211.
} 
dições atuais. Ademais, nem mesmo este sistema estaria necessariamente imune às deficiências da representação, pois a partir do momento em que se torna necessário organizar a participação, elegendo representantes dos conselhos para que estes possam ser enviados ao conselho superior, e assim por diante, essa 'nova' forma de governo pode assumir a velha forma de uma pirâmide e se tornar autoritária. ${ }^{34} \mathrm{E}$ tampouco os conselhos poderiam ser órgãos de administração e gestão, dado que, nas sociedades modernas, há necessidade de o aparelho governamental desempenhar as funções administrativas. Arendt deixa muito claro que é preciso diferenciar participação nos negócios públicos, que pode ser feita através de conselhos, e administração ou gestão de coisas de interesse público, as quais o conselho não é capaz de efetuar..$^{35} \mathrm{Em}$ suma, parece que temos razões suficientes para supor que os conselhos são recuperados por Arendt não como uma forma aplicável de governo, mas exemplos de espaços de liberdade, ação e participação efetiva do povo, que a Revolução Americana prometeu, mas não logrou garantir a longo prazo. Ela encontra neles algo que foi perdido junto com o tesouro da revolução, mas que pode e deve de alguma maneira ser recuperado, a menos que se desista inteiramente da liberdade.

A exaltação dos conselhos é acompanha da exaltação das instituições, que são a condição necessária, ainda que não suficiente, para a liberdade política. O que Arendt faz é combinar elementos liberais e democráticos, fazendo ver que liberdade e libertação não são incompatíveis, mas, ao contrário, implicam-se mutuamente. É preciso haver garantia de direitos para que haja liberdade e é preciso haver espaços de liberdade para que a "institucionalização" dos direitos seja constantemente revista e renovada. ${ }^{36}$ Este é um modo de fazer política, de ser livre e agir, que respeita a pluralidade e entende que ela só pode ser preservada no governo constitucional onde os cidadãos podem se engajar nas atividades de expressão, discussão e decisão, que são as atividades da liberdade.

\footnotetext{
${ }^{34}$ Idem, p. 222.

${ }^{35}$ Cf. Arendt, H. Da Revolução, p. 218.

${ }^{36}$ Wellmer, A. "Hannah Arendt on Revolution". In: Revue Internationale de Philosophie, vol. 53, n. 208, 1999, p. 207-22.
} 


\section{BIBLIOGRAFIA:}

ADLER, L. Nos Passos de Hannah Arendt. São Paulo: Record, 2007. ARENDT, H. Crises da República. São Paulo: Editora Perspectiva, 1973. . Da Revolução. São Paulo: Editora Ática, 1990.

A condição humana. Rio de Janeiro: Forense Universitária, 2003.

DUARTE, A. "Hannah Arendt e a exemplaridade subversiva: por uma ética pós-metafísica". In: Cadernos de Filosofia Alemã, n. 9, 2007, p.27-48.

HABERMAS, J. "Hannah Arendt's Communications Concept of Power". In: Social Research, 1977, p.3-24.

WELLMER, A. "Hannah Arendt on Revolution". In: Revue Internationale de Philosophie, vol. 53, n. 208, 1999, p. 207-22. 
